\title{
Fırtına Vadisi Meydanköy Şimşir Ormanı Arazi Karakteristiklerinin CBS Yardımıyla Tespiti ve Ekolojik Değerlendirilmesi
}

\author{
Turan YÜKSEK ${ }^{1 *} \quad$ Ali Erdem Özçelik ${ }^{1} \quad$ Bülent VEREP $^{2}$ \\ *1 Recep Tayyip Erdoğan Üniversitesi, Mühendislik ve Mimarlık Fakültesi, Peyzaj Mimarllğı Bölümü, Rize, Türkiye \\ ${ }^{2}$ Recep Tayyip Erdoğan Üniversitesi, Su Ürünleri Fakültesi, Temel Bilimler Bölümü, Rize, Türkiye
}

Atıf yapmak için: Yüksek, T., Özçelik, A.E. \& Verep, B. (2021). Fırtına Vadisi Meydanköy Şimşir Ormanı Arazi Karakteristiklerinin CBS Yardımıyla Tespiti ve Ekolojik Değerlendirilmesi. Anadolu Çev. ve Hay. Dergisi, 6(4), 674-678.

How to cite: Yüksek, T., Özçelik, A.E. \& Verep, B. (20201). Determination and Ecological Evaluation of Meydanköy Boxwood Forest Land Characteristics in Firtina Watershed Using of GIS. J. Anatolian Env. and Anim. Sciences, 6(4), 674-678.

D: https://orcid.org/0000-0003-2964-1760

(iD): https://orcid.org/0000-0001-5877-1738

(D): https://orcid.org/0000-0003-4238-8325
Öz: Hızlı sanayileşme, değişim ve aşırı tüketim çok ciddi çevresel sorunları da beraberinde getirmektedir. Artan çevre sorunları ormanlık alanlar ve hassas ekosistemler üzerinde yerel veya küresel ölçekte ciddi riskler ve sorunların oluşmasına neden olmaktadır. Bu çalışmanın amacı, dünya genelinde 200 önemli ekolojik bölgeden biri olarak tanımlanan Kuzeydoğu Anadolu coğrafyası içerisinde yer alan Fırtına vadisi Meydanköy şimșir ormanlarının arazi ve çevre karakteristiklerinin tespit edilmesi ve şimşir orman ekosistemi ile arasındaki etkileşimin ortaya konulmasıdır. Bu amaçla araştırma alanı arazi karakteristiklerine (eğim, yükselti, anakaya, meşcere karakteristikleri, drenaj ağ vb) ait verilerin analizleri Google Earth Pro ve ArcGIS 10.5 yazılımı kullanılarak gerçekleştirilmiştir. Araştırma alanı Fırtına havzası içerisinde ve Çamlıhemşin ilçe merkezine $20 \mathrm{~km}$ uzaklıktadır. Araştırma alanı 3,70 ha olup Şimşir ekosisteminin tamamı 1. derece sit alanı içinde ve mevcut alanın yaklaşık \%75-80 arasındaki bölümünün ise Kaçkar Dağları Milli Parkı içerisinde olduğu tespit edilmiştir. Araştırma alanı arazisinin vadi tabanında ve yaklaşı \% 75 'inin gölgeli bakılar üzerinde olduğu ve şimşir ekosisteminin tam ortasına trafik yoğunluğu oldukça fazla olan bir yolun geçtiği tespit edilmiştir. Koruma kullanma prensibine uygun ve bazı kısıtlarını içere alan kullanım ve yönetim modelinin oluşturulması, ekosistem içindeki bazı kızılağaçların alandan çıkarılması, alan içinden geçen yol güzergahının değiştirilerek alan dışına çıkarılması Şimşir ekosisteminin sağlığının artırılması ve sürdürülebilir yönetimi için yararlı olabilir

Anahtar kelimeler: Arazi karakteristikleri, coğrafi bilgi sistemleri, meydanköy, șimșîr.

\section{Determination and Ecological Evaluation of Meydanköy Boxwood Forest Land Characteristics in Firtina Watershed Using of GIS}

*Corresponding author's: Turan YÜKSEK

Recep Tayyip Erdoğan University, Faculty of Engineering \& Architecture, Department of Landscape Architecture, Rize, Turkey.

凶: turan.yüksek@erdogan.edu.tr

\begin{abstract}
Rapid industrialization and excessive consumption bring about very serious environmental problems. Increasing environmental problems cause serious risks and problems on forest areas and sensitive ecosystems on a local or global scale. The aim of this study is to determine the land and environmental characteristics of the Meydanköy boxwood forests in Firtına creek located in the Northeast Anatolian geography, which is defined as one of the 200 important ecological regions around the world, and to reveal the interaction between the boxwood forest ecosystem. The analysis of the data belonging to the land characteristics of the research area (slope, elevation, bedrock, stand characteristics, drainage network, etc.) was carried out using Google Earth Pro and ArcGIS 10.5 software. It has been determined that the research area is $20 \mathrm{~km}$ away from the Çamlihemşin district center in the Firtına valley, its approximate area is 3,70 ha and the entire boxwood ecosystem is within the $1^{\text {st }}$ degree protected area, and approximately $75-80 \%$ of this area is within the Kaçkar Mountains National Park. It has been determined that the research area is on the valley floor and approximately $75 \%$ of it is on shady views, and a road with a high traffic density passes right in the middle of the boxwood ecosystem. Establishing a use and management model that complies with the conservationuse principle and includes some of its limitations, removing some alder trees within the ecosystem from the area, changing the road route through the area and taking them out of the area may be beneficial for increasing the health of the boxwood ecosystem and its sustainable management.
\end{abstract}

Keywords: Boxwood, geographic information systems, land characteristics, meydanköy. 


\section{GíRiş}

İnsan sağlığı ve yaşam konforu çevre ile bağlantılıdır. Çevre koşulları, insanların fiziksel, duygusal, zihinsel ve sosyal hayatında çok önemli bir yere sahiptir. Çevre koşullarının iyi olması insanların fiziksel, zihinsel gelişimleri yanı sıra iş verimliliklerini, hayata bakış açışlarını pozitif yönden etkilemekte ve mutlu toplumların oluşmasına katkı sağlarken; olumsuz çevre koşulları ise insanların ruh ve beden sağlığ1, fiziksel gelişimi ve hayata bakış açılarını negatif yönde etkilemektedir. Bir diğer önemli husus insanların ruh ve beden sağlığı üzerinde olumlu etkiler yapan önemli ekolojik alanların olumsuz insan davranışları, hatalı planlamalar veya plansız ve aşırı kullanımlar ve küresel iklim değişimi nedenleri ile tehdit altında olmasıdır.

Dünya genelinde sahip olduğu kaynak değeri (flora, fauna, jeolojik yap1, hidroloji, sucul yap1, iklim, vb) itibarı ile öne çıkan 200 önemli karasal ekolojik bölge bulunmaktadır. Fırtına vadisi ve Meydanköy Şimşir ormanı Kafkasya-Anadolu-Hyrcanian Ilıman Ormanları olarak tanımlanan 200 önemli karasal ekolojik bölge içinde yer almaktadır (Olson \& Dinerstein, 2002). Ekolojik bölge, "o bölgeyi karakterize eden karakteristik toprak ve yeryüzü şekli kombinasyonları ile ilişkili yinelenen bir ekosistem modelidir (Brunckhorst, 2000). Bu ekosistemlerin sahip olduğu kaynak değerlerinin korunması, koruma-kullanma dengesine göre faydalanılması sürdürülebilir yönetim için çok önemlidir.

Bu çalışmanın amacı Fırtına havzası Meydanköy Şimşir ormanların yayılış alanı arazi karakteristiklerinin (yükselti, eğim, bakı vb) coğrafi bilgi sistemleri (CBS) ile belirlenmesi ve şimşir ormanların kurumasına etki eden risk unsurlarının ekolojik ilkeler dikkate alınarak irdelenmesidir.

\section{Araştırma Sahası Coğrafi Konumu ve Bazı}

İklim Özellikleri: Çalışma konusu olarak seçilen araştırma alanı Fırtına deresi yağış havzasında ve tarihi Zilkale'ye $7,7 \mathrm{~km}$, Çamlıhemşin ilçe merkezine $20 \mathrm{~km}$ uzakl1kta, $40^{\circ} 54^{\prime} 25^{\prime \prime}-40^{\circ} 54^{\prime} 30^{\prime \prime}$ kuzey enlemleri ile $40^{\circ} 56^{\prime} 50^{\prime \prime}-40^{\circ} 57^{\prime} 00^{\prime \prime}$ doğu boylamları arasinda yer almaktadır (Şekil 1). Araştırma alanı içinde veya yakın çevresinde bir meteoroloji istasyonu olmadığı için iklim verilerinde Pazar Meteoroloji İstasyonu verileri ile araştırma alanı ile yaklaşık aynı yükselti kademesinde ve komşu havzada yer alan Ayder Awos verilerinden yararlanılmıştır. Araştırma alanı yıllık ortalama sıcaklığı $8,6{ }^{\circ} \mathrm{C}$, ortalama sicaklık değerine göre en sicak ay Temmuz $\left(18,6{ }^{\circ} \mathrm{C}\right)$, en soğuk ay Ocak $\left(-2,4{ }^{\circ} \mathrm{C}\right)$ tır (Yüksek, 2013). 2013-2019 Ayder Awos verilerine göre yıllık toplam yağış miktarı 958 mm'dir (Yüksek vd., 2020).

\section{MATERYAL VE METOT}

Materyal: Araştırma alanı Google Earth Pro, korunan alanlar veri tabanı, orman amenajman planı, jeolojik yapı veri tabanı ve ArcGIS 10.5 yazılımı bu çalışmanın ana materyallerini oluşturmaktadır.

Yöntem: Araştırma alanı arazi karakteristiklerine (eğim, yükselti, anakaya, meşcere karakteristikleri, drenaj ağ1, vb) ait verilerin analizleri Google Earth Pro ve ArcGIS 10.5 yazılımı kullanılarak gerçekleştirilmiştir. Araştırma alanına ait diğer ekolojik gözlemler alan içi ve çevresinde yapılan arazi çalışmaları ile yürütülmüştür.

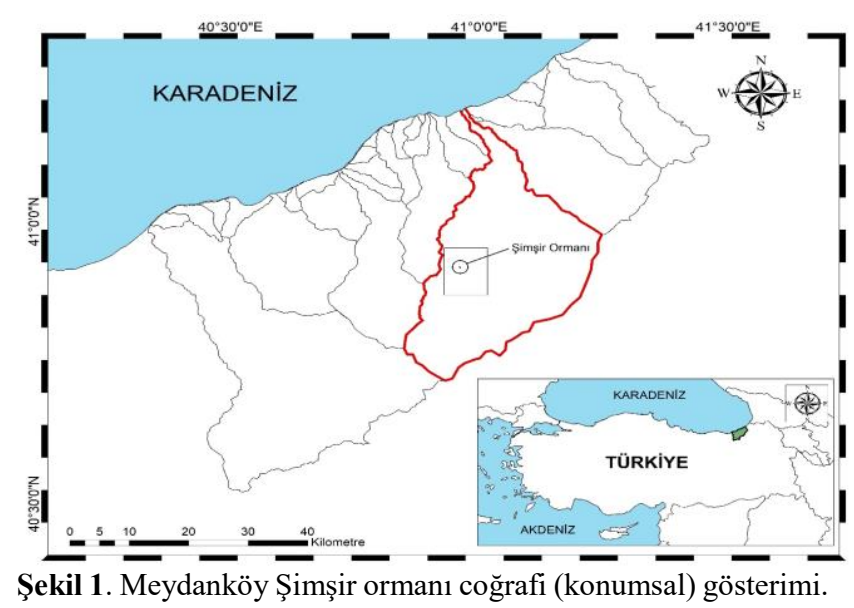

Figure 1. Geographical location of Meydanköy Boxwood forest

\section{BULGULAR}

Şimşir ekosisteminin sahip olduğu alan yaklaşık 3,70 hektar olup, şimşir ekosistemin tamamı 1. derece sit alanı içindedir. Şimşir ekosistem alanın 2,85 hektarı (\%77,03) Kaçkar Dağları Milli Park Sınırları içerisinde kalmaktadır. Araştırma alanının tamamı Kumlu tüfAndezit-Bazalt lav ve Piroklastları kayaç gurubu üzerindedir (Şekil 2). Araştırma alanı 991-1048 m yükseltileri arasında yer almaktadır (Şekil 3).

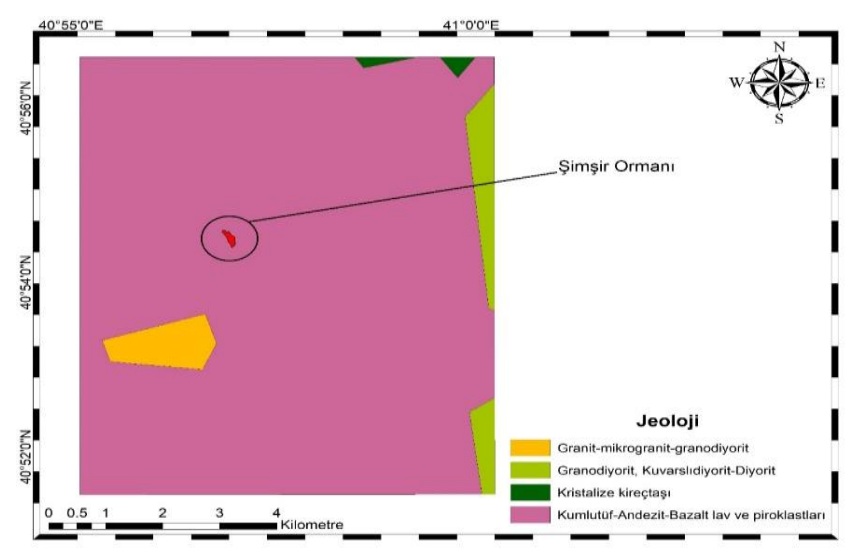

Şekil 2. Araştırma alanı kayaç guruplarının dağılımı.

Figure 2. Distribution of rock groups in the study area. 


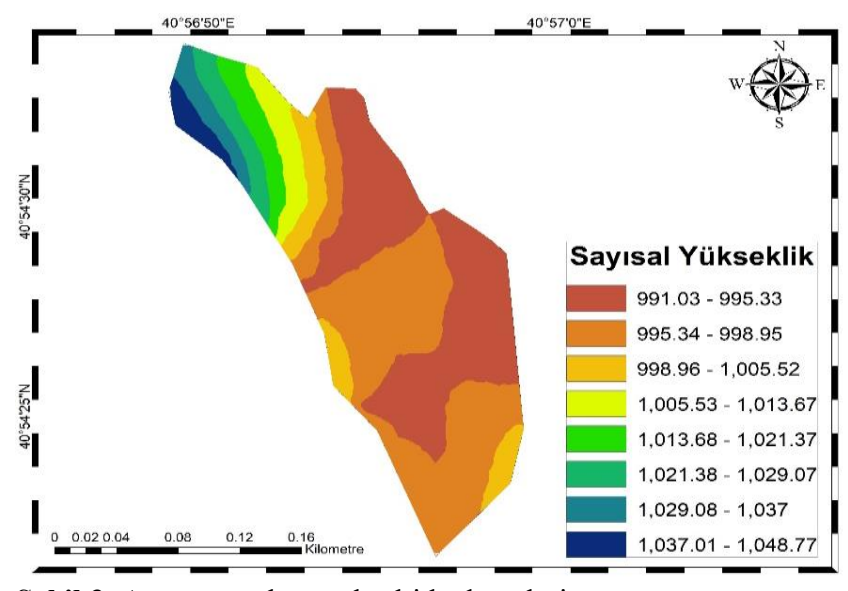

Şekil 3. Araştırma alanı yükselti kademeleri.

Figure 3. Elevation levels in the study area.

Araştırma alanındaki arazilerin \%75,15'i gölgeli bakılar, \%24,85'i güneşli bakılar üzerindedir. En az arazi varlığı \%4 ile güney bakıda, en yüksek arazi varlığı \%28,06 ile doğu bakı üzerindedir (Şekil 4).

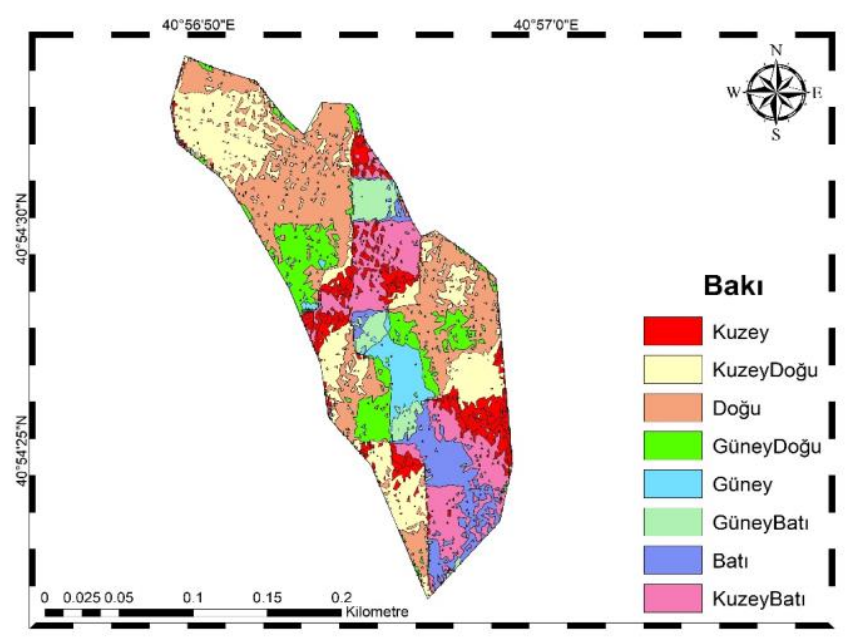

Şekil 4. Araștırma alanı bakı dağılım haritası.

Figure 4. Aspect groups in the research area.

Araştırma alanı eğimi \%1-20 arasında değişmektedir. Alan içerisindeki eğim güneyden kuzeye doğru gidildikçe artmaktadır (Şekil 5).

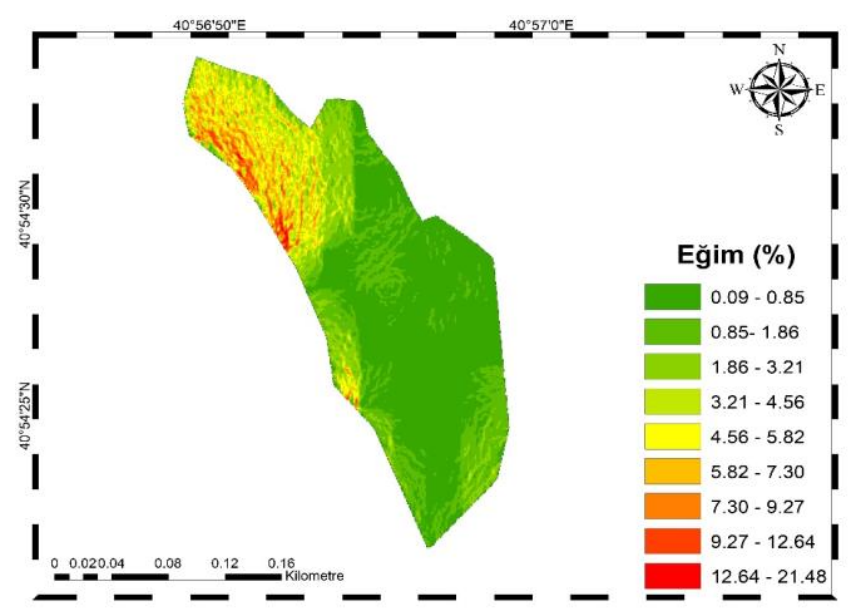

Şekil 5. Araştırma alanı eğim gurupları.

Figure 5. Slope groups in the study area.
Şimşir ormanlarının içerisinde münferit halde Ilex colchica Pojk, Hedera colchica (C.Koch), Pteridium aquilinum (L.), Phyllitis scolopendrium (L.), Rubus sp. (Aksoy, 1995), münferit halde değişik yaşlı kızılağaç, Carex sp, Juncus sp., türleri bulunmaktadır. Şimşir meşceresinin etrafında değişik gelişim çağlarda kayın+ladin, kayın+kızılağaç, kayın+ladin+kızılağaç, bozuk kayın ve kızılağaç meşcereleri ve bu meşcereler içinde münferit veya küçük guruplar Castanea sativa Mill., Rhododendron ponticum L., Rhododendron luteum L., türler yer almaktadır (Şekil 6). Araştırma alanı şimşir ormanı çevresi zengin bir drenaj ağına sahiptir. Şimşir ekosisteminin güney bölümü dere yatağı içinde kalmaktadır (Şekil 7).

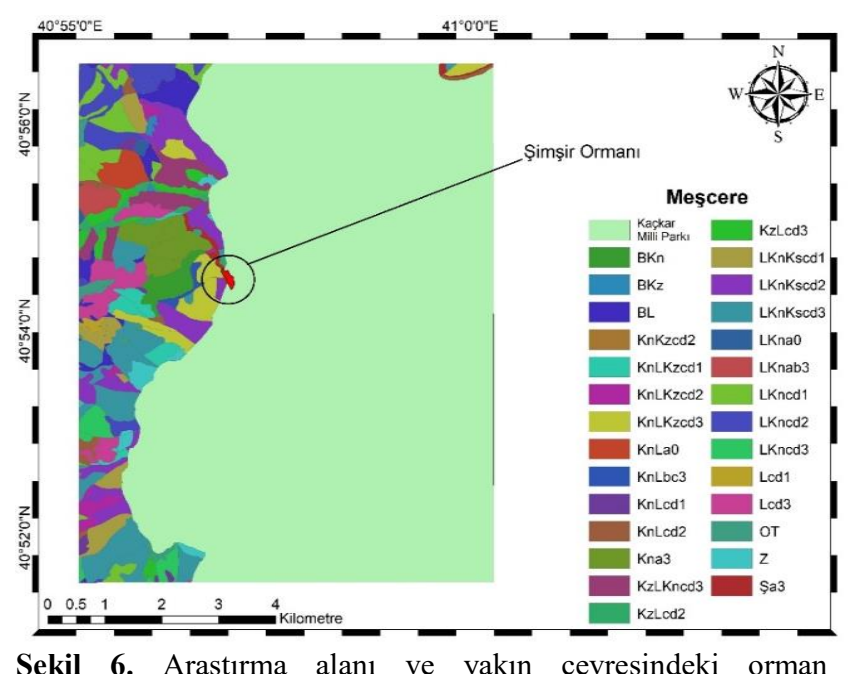

Şekil 6. Araştırma alanı ve yakın çevresindeki orman toplumlarının dağılımı.

Figure 6. Distribution of forest communities in and around the study area.

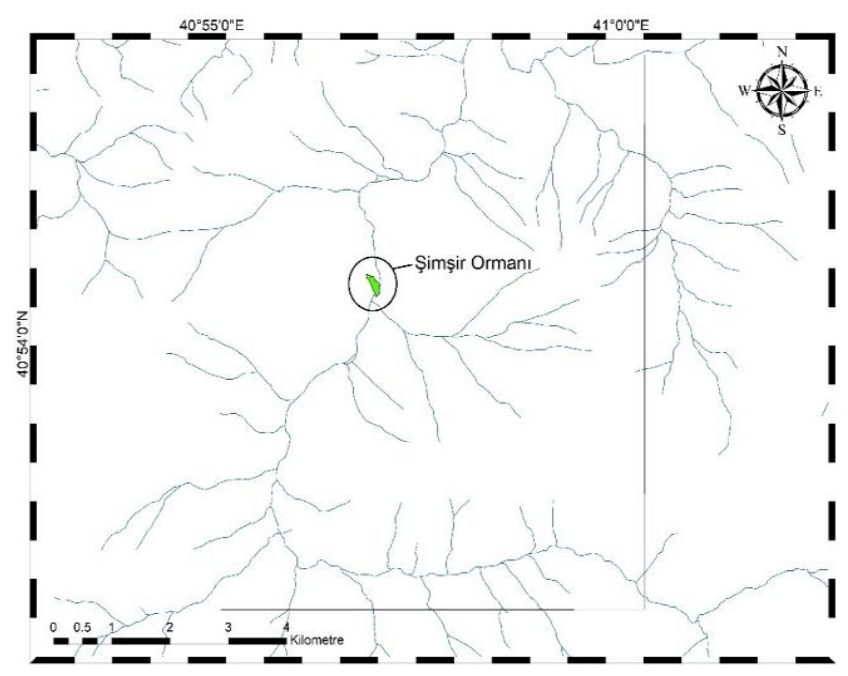

Şekil 7. Şimşir ormanı ve çevresindeki drenaj ağının dağılımı.

Figure 7. Distribution of drainage network in and around the boxwood forest.

Araştırma alanı şimşir ormanlarının içinden Çamlıhemşin ilçesinin köylere ve yaylalara bağlayan yol geçmektedir (Şekil 8). 


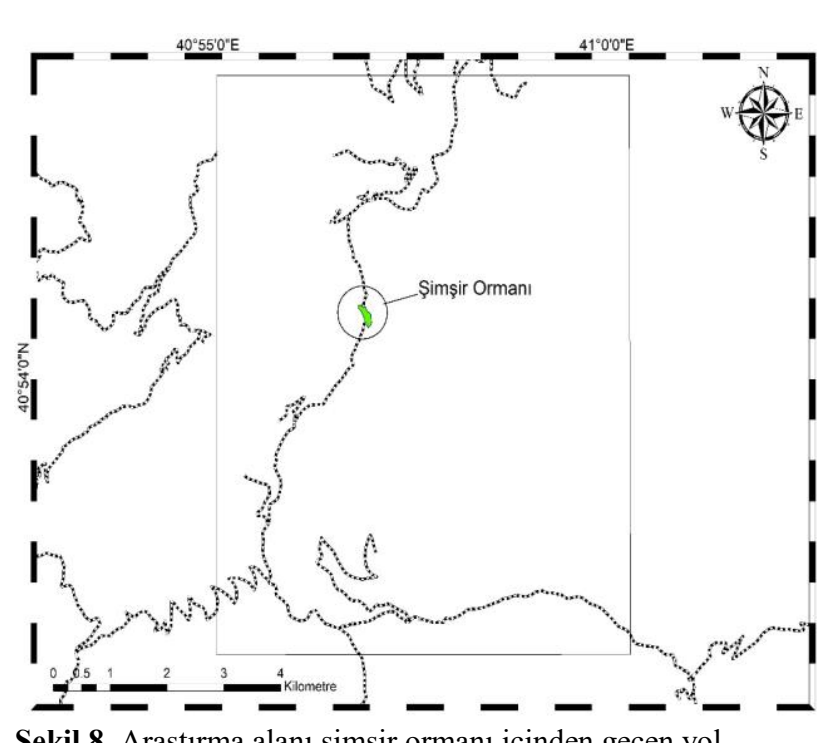

Şekil 8. Araştırma alanı şimşir ormanı içinden geçen yol.

Figure 8. The road through the boxwood forest of the study area.

\section{TARTIŞMA VE ÖNERILER}

Fırtına vadisi şimşir ekosistemi kendine has yapısı, komşu çevreye ait diğer zengin kaynak değerleri ile sadece ülkemizin değil, tüm dünya karasal ekosistemin çok önemli bir parçasıdır. Şimşir ekosistemi Fırtına vadisi içinde kuzey-güney yönünde çok yoğun ekoturizm faaliyetlerinin yürütüldüğü bir alanda olması, şimşir ekosisteminin içinden yol geçmesi nedeniyle her zaman taşıma kapasitesinin çok üzerinde yoğun bir ziyaretçi trafiğine maruz kalmakta ve alana her mevsim gelişigüzel erişim yapılmaktadır. Araştırma alanı şimşir ekosisteminin tamamı 1. derecede sit alanı içinde ve ayrıca alanın büyük kısmı milli parklar içinde yer almasına rağmen alana ait herhangi bir koruma ve kullanma planı bulunmamaktadır. Şimşir ekosisteminde kontrolsüz kamp yapılması, kamp ateşi, piknik, çöplerin bırakılması, düğün, nişan veya diğer amaçlı resim çekimleri, okul gezileri, vb aktiviteler ile bir yandan diğer ortamlardaki kirleticiler bu hassas ekosisteme taşınırken diğer yandan yoğun ziyaretçi trafiği ile toprak özelliklerinin (toprak sıkışması, hacim ağırlığının artması, infiltrasyonun azalması, vb) bozulmasına yol açmaktadır. Yapılan araştırmalarda (Vimmerstadt vd., 1982; Gent \& Ballard, 1985; Gül \& Atken, 2005; Yüksek vd., 2008; Yüksek vd., 2010a; Yüksek vd., 2010b;) farklı tip orman ekosistemlerdeki ziyaretçi trafiğinin artması ile toprak özelliklerinin ve vejetasyon yapısının (Kerbiriou vd., 2008; Yüksek, 2009) önemli derecede tahrip olduğu ortaya konulmuştur. Şimşir ekosistemi içinden trafik yoğunluğu fazla olan yolun geçmesi ve araçlardan salınan emisyonlar şimşir ekosistem sağlığının bozulmasına neden olmaktadır. Yapılan araştırmalarda trafik yoğunluğu ve artan emisyon salınımı ile bitkilerin yaprak yüzeylerinin tahrip olduğu (Çepel, 1997), büyümenin olumsuz etkilendiği (Kabir vd., 2012) ve ekosistem sağlığının bozulduğu tespit edilmiştir. Şimşir ekosisteminin meşcere kapalılığının artması, meşcere içine ulaşan güneş enerjisi miktarının azalması, ölü örtü birikiminin artması, meşcere drenaj yapısının bozulması ve küresel iklim değişiminin olumsuz etkileri nedeniyle meşcere sağlığı hızlı bir şekilde bozulmuştur. Nitekim yapılan araştırmalarda toprak sıcaklığının ve yağışın artması ile birlikte mantar popülasyonunun arttığ ortaya konulmuştur (Biederbeck \& Campbell, 1971; Davies, \& Whitbread, 1989). Şimşir ekosistemi içinde kısmı aralama yapılması ve ekosistemdeki kızılağaçların bir kısmının alandan çıkarılması şimşir ekosistemindeki zararlı mantar popülasyonlarının kontrol altına alınabilmesi için yararlı olabilir. Yine alanda yürütülecek drenaj çalışmaları ile topraktaki nemin mantar popülasyonlarını dengeleyecek düzeye düşürülebilir. Bunun sonucunda mantar popülasyonlarının şimşir ekosistem için tehdit oluşturması ve dahası şimşir ölümlerine neden olması engellenebilir. 1. Derecede sit alanı olan ve ayrıca alanın büyük bir kısmının Kaçkar Dağları Milli Parkı sınırları içindeki Meydanköy şimşir ormanlarının kullanılmasında koruma kullana ilkesi hassas bir şekilde uygulanmalı, alana kontrollü ve taşıma kapasitesini geçmeyen kısıtlı bir erişim sağlanmalıdır. Dış paydaş kaynakları kirleticilerin alana erişimini engellemek için orman girişinde kontrol noktasında hijyen önlemleri (ziyaretçi galoş, steril su vb) alınabilir. Alan içinde ziyaretçi gezisi için ahşaptan yürüme ve dinlenme, resim çekme alanları oluşturmak suretiyle ziyaretçilerin şimşir ekosistemi üzerindeki riskler azaltılabilir. Buna ilaveten şimşir ekosistemi içinden geçen yol güzergahı değiştirilmeli ve şimşir ekosistemi dışına çıkarılmalıdır. Bu uygulamalar sonucunda şimşir ekosistem sağlığ üzerindeki riskler azaltılmış ve şimşir ekosisteminin sürdürülebilirliği sağlanmış olabilir.

\section{KAYNAKLAR}

Aksoy, N. (1995). Furtına vadisi'ndeki Buxus sempervirens toplumlarının yayılışı ve floristik bakımdan incelenmesi. I. Ulusal Karadeniz Ormancllk Kongresi, 23-2 5 Ekim Trabzon, Türkiye, 7-15.

Biederbeck, V.O. \& Campbell, C.A. (1971). Influence of simulated fall and spring conditions on the soil system. I. Effect on soil microflora. Soil Science Society of America Journal, 35(3), 474-479.

Brunckhorst, D. (2000). Bioregional planning: resource management beyond the new millennium. Published by Routledge, 200p.

Çepel, N, (1997). Toprak kirliliği erozyon ve çevreye verdiği zararlar. TEMA Vakfı Yayın No:14, İstanbul, $111 \mathrm{~s}$.

Davies, K.G. \& Whitbread, R. (1989). Factors affecting the colonisation of a root system by fluorescent 
Pseudomonads: The effects of water, temperature and soil microflora. Plant and Soil, 116, 247-256.

Gent, J.A. \& Ballard, R. (1985). Impact of intensive forest management practices on the bulk density of lower Coastal Plain and Piedmont soils. Southern Journal of Applied Forestry, 9, 40-44.

Gül, A. \& Atken, M. (2005). Korunan doğal alanlarda rekreasyonel taşıma kapasitesi ve kavramsal Yaklaşımlar. Korunan Doğal Alanlar sетроzуити, 8-10 Eylül 2005, Isparta, Türkiye, 485-494.

Kabir, M., Iqbal, M.Z. \& Shafiq, M. (2012). Traffic density, climatic conditions and seasonal growth of Samanea saman (Jacq.) Merr. On different polluted roads of Karachi city. Pakistan Journal of Botany, 44(6), 1881-1890.

Kerbiriou, C., Leviol, I., Jiguet, F. \& Julliard, R. (2008). The impact of human frequentation on coastal vegetation in a biosphere reserve. Journal of Environmental Management, 88, 715-728.

Olson, D. M. \& Dinerstein, E. (2002). The Global 200: Priority ecoregions for global conservation. Annals of the Missouri Botanical Garden 89(2), 199-224.

Yüksek, T. (2009). Effect of visitor activities on surface soil environmental conditions and aboveground herbaceous biomass in Ayder Natural Park. CLEAN Soil, Air, Water, 37(2), 170-175.

Yüksek, F. (2013). Fırtına deresi havzasında doğal olarak yetişen Ayı Üzümü (Vaccinium arctostaphylos L.) populasyonlarında bazı ekolojik faktörlerin bitki ve meyve özelliklerine etkisi üzerine araştırmalar. Doktora Tezi, KTÜ Fen Bilimleri Enstitüsü. Trabzon, Türkiye, 182s.

Yüksek, T., Özçelik, A.E. \& Verep, B. (2020). Fırtına Havzasının Bazı Havza Karakteristikleri ile Arazilerin Fizyografik Özelliklere Göre Dağılımlarının Coğrafi Bilgi Sistemleri ile Belirlenmesi. Journal of Anatolian Environmental and Animal Sciences, 5(3), 439449.

Yüksek, T., Cengiz, T. \& Yüksek, F. (2008). Doğal alanlarda festival etkinliklerinin korumakullanma açısından değerlendirilmesi: Kafkasör Kültür, Sanat ve Turizm Festivali Örneği. Ekoloji, 17(67), 37-45.

Yüksek, T., Kurdoglu, O. \& Yüksek, F. (2010a). The effects of land use changes and management types on surface soil properties in Kafkasör protected area in Artvin, Turkey. Land Degradation \& Development, 21(6), 582-590.
Yüksek, T., Yüksek, F., Eyüpreisoğlu, M., Erdoğan Yüksel, E., \& Sütlü, E. (2010b). Effect of visitor activities on topsoil hydrophysical properties in two protected areas in northern blacksea region. $1^{\text {st }}$ International Turkey \& Japan Environment And Forestry Symposium, 04-06 November, Trabzon, Turkey, 264-280.

Vimmerstadt, J., Scoles, F., Brown, J. \& Schmittgen, M. (1982). Effects of use pattern, cover, soil drainage class and overwinter changes on rain infiltration on campsites, Journal of Environental Quality, 11, 25- 28. 